\title{
Tip 2 Diyabetli Hastalarda Pedigri Genetik Risk Analizi İle Yaşam Kalitesi İlişkisinin
} Incelenmesi

\author{
Öğr. Gör. İbrahim Caner Dikici ${ }^{1}$, Prof. Dr. Nermin OLGUN ${ }^{2}$, Uzm. Hem. İnci ARPACI EREN ${ }^{3}$ \\ ${ }^{1}$ Harran Üniversitesi Sağlık Bilimleri Fakültesi, Hemşirelik AD. İç Hastalıkları Hemşireliği, ŞANLIURFA \\ ${ }^{2}$ Hasan Kalyoncu Üniversitesi Hemşirelik Anabilim Dalı Iç Hastalıkları Hemşireliği, GAZiANTEP \\ ${ }^{3}$ Şehitkamil Devlet Hastanesi Diyabet Polikliniği, GAZIANTEP
}

DOI:http://dx.doi.org/10.29228/tjdn.52470

\section{Araştırma}

Sorumlu Yazar
Ibrahim Caner DikiCi
Tel: 05376729057
E-mail:
ibrahimcanerdikici@gmail.com

ibrahim Caner Dikici

ORCID: 0000-0002-9838-4502

\section{Nermin OLGUN}

ORCID: 0000-0002-8704-4588

\section{Inci ARPACI EREN \\ ORCID: 0000-0003-1522-1714}

Geliş tarihi: 26.08.2021

Kabul tarihi: 20.12.2021

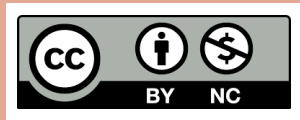

\section{Özet}

Çalışma, tip 2 diyabetli hastalarda pedigri genetik risk analizi ile yaşam kalitesi ilişkisinin incelenmesi amacıyla yapıldı. Bu çalışmanın örneklemini Şehitkamil Devlet Hastanesi endokrin polikliniğinde ve dahiliye ünitelerinde Mayıs 2018-Eylül 2019 tarihleri arasında hastaneye başvuran 95 tip 2 diyabet hastası oluşturdu. Veriler; sosyo-demografik tanıtıcı özellikleri içeren soru formu, hastalık, tedavi ve ailede genetik risk ile ilgili bilgilere yönelik tanıtıcı bilgi formu, Ferrans ve Powers'in Yaşam Kalitesi Endeksi Diyabet Version-3 anket formu ile yüz yüze görüşme tekniği ile

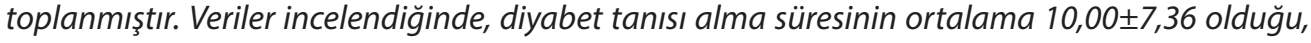
Pedigri analizine göre hastalığın \%45,3'ünde hiç tekrarlanmadığı, \%37,9'unda ise 1. dereceden kişilerde görüldüğü ve \%57,9'unda anne-babanın aynı köylü olduğu belirlendi. Hastalarda, ailede diyabet varlığı ile diyabet yaşam kalitesi indeksi sağık ve fonksiyonel durum alt boyutu puan ortalamaları arasında 1. ve 2. dereceden aile içinde görülmesinde istatistiksel olarak anlamlı fark belirlendi. Hastalık gelişmeden önceki dönemde risk altındaki bireylerin yönetiminin sağlaması ve soy geçmiş öyküsünün tanılamasının maliyet açısından etkin sonuçlar ortaya çıkaracağı tahmin edilmektedir. Pedigri risk analizinin klinikteki çalışmalarda kullanımı önerilebilir.

\section{Anahtar Sözcükler: Tip 2 diyabet; Pedigri; Genetik Risk; Yaşam Kalitesi}

\section{Abstract}

The study was conducted to examine the relationship between pedigree genetic risk analysis and quality of life in patients with type 2 diabetes. The sample of this study consisted of 95 type 2 diabetes patients who were admitted to the hospital between May 2018 and September 2019 in the endocrine polyclinic and internal medicine units of Şehitkâmil State Hospital. Data; a questionnaire containing socio-demographic introductory features, an introductory information form for information about the disease, treatment and genetic risk in the family, Ferrans and Powers' Quality of Life index Diabetes Version-3 questionnaire form and face-to-face interview technique were collected. When the data is examined, the mean time to be diagnosed with diabetes was $10.00 \pm 7.36$, according to the Pedigree analysis, the disease did not recur in $45.3 \%$ of the patients, and in $37.9 \%$ of the patients with 1st degree. It was determined that the parents were the same villager in $57.9 \%$ of the cases. A statistically significant difference was found between the presence of diabetes in the family and the mean scores of the diabetes quality of life index health and functional status sub-dimension in patients with 1st and 2nd degree familial occurrences. It is estimated that the management of individuals at risk and the diagnosis of family history in the period before the disease develops will result in cost-effective results. The use of pedigree risk analysis in clinical studies can be recommended.

Keywords: Type 2 Diabetes; Pedigree; Genetic Risk; Quality of Life 


\section{Giriş}

Diyabet, sadece gelişmiş ülkelerde değil, aynı zamanda gelişmekte olan ülkelerde de artan hasta sayısı ile bir salgın haline gelmiştir. Tip 2 diyabet, insülin direncine ve bozulmuş insülin sekresyonuna bağlı hiperglisemi ile karakterize en yaygın diyabet şeklidir (Yu, 2012). Diyabet prevalansındaki artışın çoğunun, son birkaç on yıldaki yaşam tarzı ve zamana bağlı değişikliklerin bir sonucu olduğu açıkça görünse de bu karmaşık hastalıkta genetik yatkınlığın da çok önemli rolü vardır (Barroso, 2005). Yapılan bir çalışmada, tip 2 diyabet patogenezinde etnik heterojenliğin varlığını göstermektedir (Yu, 2012). Tip 2 diyabet genetik yatkınlık zemininde çevresel faktörlerin (aşırı kilo alımı, sağlıksız beslenme, fiziksel aktivite eksikliği) uzun yıllar süren etkisiyle ortaya çıkmaktadır (Olgun vd., 2014). Tip 2 diyabet, çevresel faktörler ile güçlü bir kalıtsal bileşen arasındaki etkileşimin sonucudur (Barroso, 2005).

Genetik yatkınlığı olan bireylerin patogenezinde beta hücresi fonksiyon bozukluğu, hepatik glikoz üretimi artışı ve insülin direnci gibi üç ana metabolik bozukluk neden olmaktadır. Dünyada giderek artmakta olan diyabetin görülme sıklığı genetik özellikler başta olmak üzere yaş, cinsiyet, ırk, beslenme alışkanlıkları ve çevresel etkenlere bağlı olarak toplumdan topluma farklılık göstermektedir (Yalın vd. 2011). Genetik taramalarda ailesinde (özellikle birinci derece yakınlarında) diyabeti olan bireylerin diyabet gelişme riskinin önemli oranda arttığı bulunmuştur (Arıkoğlu, 2015).

İnsan genom araştırmalarındaki son gelişmeler, bireysel genlerin keşfini hızlandırmıştır. Genleri analiz etme ve insan genetik bozukluklarından sorumlu spesifik kusurları tespit etme olasılığı, genetik testin klinik uygulamanın ayrılmaz bir parçası haline geldiği noktaya gelmiştir (Yoo, 2010). Genetik test, kalıtsal hastalıkla ilişkili genotipleri, mutasyonları, fenotipleri veya karyotipleri klinik amaçlar için tespit etmek amacıyla insan DNA, RNA, kromozomlar, proteinler ve bazı metabolitlerin analizi olarak tanımlanır (McPherson, 2006).

Pedigri Genetik risk tabanlı çalışmalar epidemiyolojinin belirlenmesinde önemli rol oynarlar. Tip 2 diyabet hastalarında pedigri ile yapılan çalışmalar genetik olarak hastalığın nesiller boyunca aktarılması hakkında bilgi veren çalışmalardır Epidemiyolojik çalışmalar, hastaların aile geçmişi ile soy geçmişi üzerine yoğunlaşmıştır (Karadağ ve Aktaş, 2017) Bazı çalışmalarda, bireyin aile üyelerinden birinin tip 2 diyabete sahip olması durumunda, diyabet gelişme riskinin artabileceği gösterilmiştir (Chernausek ve vd. 2016; Raghavan ve vd. 2016)

Sağlık profesyonelleri, risk değerlendirmesi ve tanı koymanın yanı sıra genetik durumu riskli olan hastaların semptomlarının ve psikososyal bakımının yönetiminde yer almaktadır (Saleh, 2019) İnsan genom araştırmasındaki son gelişmeler, bireysel genlerin keşfedilmesini hızlandırmıştır. Bu gelişme aynı zamanda genlerin nasıl birlikte çaış̧ığını ve genetik bozuklukların hastalığın gelişimine nasıl yol açtığının anlaşılmasını da arttırmıştır (Wook, 2010).

Genetik / genomik hakkında bilgi sahibi olan ve aile öyküsünde risk değerlendirme becerisine sahip hemşireler, erişkinlerde ortaya çıkan bozukluklar nedeniyle ortaya çıkan morbidite ve mortaliteyi önleme potansiyeline de sahiptir. Amerika Birleşik Devletleri'nde en önemli on ölüm nedeninin hepsinde kalp hastalığı, kanser, serebrovasküler hastalık ve diyabete bağlı ölümlerin büyük çoğunluğunda genetik ve/veya genomik bir bileşen bulunmaktadır (Calzone, 2013).

İnsanlarda, APOE (Apolipoprotein E) gibi genler hem tip 2 diyabet hem de bilişsel fonksiyon ile ilişkili bulunmuştur. Bu da ortak gen etkilerinin tip 2 diyabet ve bilişsellik arasındaki bazı teorik bir ilişkiden kaynaklanabileceğini göstermektedir (Luciano, 2014). İnsan genomunun dizileme ile birlikte yetişkin bireylerde çok sayıda yeni tarama testleri (kanser tarama, kardiyovasküler hastalıklara yatkınlık paneli, diyabet hastalığına yatkınlık) kullanımaktadır. Tip 2 diyabette genetik ile ilişkili olarak risk altında bulunan bireylere ve/veya ailelere tanı, araştırma yöntemleri, korunma, tedavi ve sosyal destek gibi konularında pedigri analizi kullanılmaktadır (Durmaz vd. 2011).

İleri teknolojiler kullanan ve öncelikle Kafkasyalı hastaları kapsayan genom çapında ilişkilendirme çalışmalarında (GWAS), 120'den fazla tip 2 diyabet ile ilişkili genomik lokus tanımlamış ve çoğunun beta hücresi fonksiyonuna önemli ölçüde katkıda bulunduğu gösterilmiştir (Kong, 2017). Bu çalışma, Tip 2 diyabetli hastalarda pedigri genetik risk faktörleri ile yaşam kalitesi arasındaki ilişkisinin incelenmesi amacıyla yapıldı.

\section{Gereç ve Yöntem}

Çalışma tanımlayıcı nitelikte olup Mayıs 2018-Eylül 2019 tarihleri arasında Şehitkâmil Devlet Hastanesi'nde yürütüldü. Çalışmanın örneklemini diyabet polikliniği ve dâhiliye ünitelerinde en az 6 ay tip 2 diyabet tanısı almış ve iletişim engeli bulunmayan 95 diyabet hastası oluşturdu.

Verilerin toplanmasında, hastalar için hazırlanan sosyo-demografik veri toplama formları, tip 2 diyabetlilerde Pedigri Genetik risk ile ilgili sorular ve Ferrans ve Powers'in Yaşam Kalitesi Endeksi Diyabet Version-3 soru formları kullanıldı. Çalışmada literatür taranarak sosyo-demografik veri toplama formları ve pedigri genetik riskile ilgili sorular alanında uzman ve literatür doğrultusundahazırlandı.Veritoplama, 15-20dakikadatamamlandı.

Araştırmanın yapılabilmesi için 06.11.2018 tarihinde 2018/08 nolu karar ile Hasan Kalyoncu Üniversitesi Etik Kurulu'ndan ve hastaneden yazılı olarak kurum izni alındı. Ayrıca, katılımcılara araştırmanın amacı açıklanmış olup, gönüllü olarak katılmayı kabul eden hastalar ile gerçekleştirildi.

Sosyo-demografik, hastalığa ilişkin sorular ve genetik riske ilişkin soru formu

Araştırmacılar tarafından literatür doğrultusunda sosyodemografik ve hastalığa ilişkin 15 soruyu içeren; yaş, cinsiyet, medeni durum, eğitim durumu, çalışma durumu soruları ile; hastalığa ilişkin veriler ise; kronik hastalık varlığı, ailede kronik sağlık öyküsü, hastalık süresi, hastalık tipi, diyabet tedavi şekli, egzersiz yapma durumları, düzenli ilaçlar kullanma durumu, Sigara ve alkol kullanma durumu ve metabolik kontrol değişkenlerini (BKI, boy-kilo, AKŞ, TKŞ, HbA1C, HDL, LDL vb.) içeren soru formu kullanıldı. Tip 2 diyabet hastalarında genetik riske yönelik; hastalığın ilk başlangıç yaşı, aile içinde tekrar sayısı, ailede akraba evliği varlığı, kronik hastalık varlığı, aile içinde görülme sıklığı, hastalık nedeniyle ailede ölüm varlığı ve yaşı, ailenin etnik kökeni, 1.ve 2. dereceden ailenin sağlık durumu (anne, baba, çocuk, amca, dayı, teyze vb.) ve anne-babanın aynı köylü olma durumuna yönelik genetik yönünden dağılımlarını içeren 14 soru ile veriler toplandı.

\section{Ferrans ve Powers Yaşam Kalitesi Endeksi Diyabet} Version-3

Ölçek 1984 yılında Carol Estwing Ferrans ve Marjorie Powers tarafından yaşam kalitesini, memnuniyet ve önem üzerine değerlendirmek amacıyla geliştirilmiştir. Türkçe geçerlik ve güvenirlik çalışması Canlı Özer ve Efe tarafından yapılmıştır. Ölçek toplam 34 madde memnuniyet, 34 madde önem sorusu üzerinden oluşmaktadır. Ölçek maddeleri 1'den 6'ya kadar likert tipi puanlama ile 
derecelenmiştir. Ölçek, sağlık ve fonksiyonel durum, sosyal ve ekonomik durum, fizyolojik ve manevi durum ve aile durumu olmak üzere 4 alt boyuttan oluşmaktadır. Her bölüm için 0-30 arasında puan elde edilmektedir. Ölçekten alınan puanlar ne kadar yüksekse yaşam kalitesi o oranda yüksektir (Ferrans, 2008).

\section{Verilerin Analizi}

Verilerin değerlendirilmesinde, SPSS (Statistical Package for Social Sciences) 17.0 paket programı kullanıldı. Verileri analizinde ortalama, standart sapma, min-max tanımlayıcı istatistiksel yöntemler kullanılmıştır. Ölçeğin dağılımları, Kolmogorov Simirnov testi ile normallik dağılımlarına bakılmıştır. Normal dağılım göstermeyen çalışmada, veriler Kruskal Wallis, Ki Kare testi ve Pearson Correlation ile karşılaştırılarak analizi yapıldı. Verilerin, $\mathrm{p}<0.05$ anlamlılık düzeyleri değerlendirildi.

\section{Bulgular}

Araştırmada, hastaların çoğunluğu 50-60 yaş aralığında ve kadındır (\%65,8). Hastaların \%94,7'si evli olup \%92,6'sı eş ve/veya çocukları ile yaşamakta, \%57,9'u okuryazar değil, $\% 85,3$ 'ü ev hanımı/emekli ve \%90,5'i çalışmamaktadır (Tablo 1).

Araştırmada, diyabetli hastaların tanımlayıcı özellik-

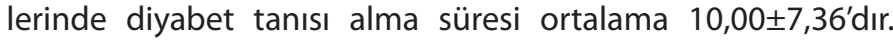
Hastaların, \%83,2'sinde diyabetle beraber eşlik eden herhangi bir kronik hastalık bulunmamaktadır. Hastaların, \%55,8'i her zaman düzenli ilaç kullandığı, \%38,9'inde ise kontrollere her zaman düzenli gittiği belirlendi. Hastaların, diyabet tedavi şeklinde, \%16,8'i tıbbi beslenme tedavisi, \%18,9'u oral anti diyabetik ilaç (OAD), \%34,7'si insülin ve \%44,2'sinde ise insülin + OAD tedavisi uygulandığı belirlendi (Tablo 2).

Hastaların beden kütle indeksi (BKI) incelendiğinde, \%70,5'i obez, \%20'si kilolu ve \%9,5'i normal kilodadır. Cinsiyetlerine göre AKŞ dağılımına bakıldığında ise; kadınlarda ortalama $209,66 \pm 99,53$, erkeklerde ise $220,75 \pm 80,28$ olduğu, TKŞ dağılımlarında kadınlarda ortalama 271,98 $\pm 89,53$, erkeklerde ise $291,33 \pm 108,64$ olduğu belirlendi (Tablo 3)

Pedigri risk analizine, göre hastalığın \%37,9'u 1. dereceden, \%2,1'i2. dereceden \%14,7'si 1.ve2.derecedenakrabalarda görülmektedir. Hastaların 29,5'inin akraba evliliği olduğu, \%42,1'inin anne babasının aynı köylü olduğu ve \%22,1'inin ailesinde kronik hastalık nedeniyle ölüm görüldüğü saptandı (Tablo 4)

\begin{tabular}{|c|c|c|c|}
\hline & & $n$ & $\%$ \\
\hline \multirow{3}{*}{$\begin{array}{l}\text { Eşlik eden kronik } \\
\text { hastalık varlığı }\end{array}$} & Yok & 79 & 83,2 \\
\hline & Var & 16 & 16,8 \\
\hline & $\begin{array}{l}\text { Tıbbı beslenme } \\
\text { tedavisi }\end{array}$ & 16 & 16,8 \\
\hline \multirow{3}{*}{$\begin{array}{l}\text { Diyabet tedavi } \\
\text { şekli }\end{array}$} & OAD & 18 & 18,9 \\
\hline & İnsülin & 33 & 34,7 \\
\hline & OAD + İnsülin & 42 & 44,2 \\
\hline \multirow{2}{*}{$\begin{array}{l}\text { Kontrollere gitme } \\
\text { durumu }\end{array}$} & Her zaman & 37 & 38,9 \\
\hline & Bazen & 58 & 61,1 \\
\hline \multirow{2}{*}{$\begin{array}{l}\text { İlaçları düzenli } \\
\text { kullanma durumu }\end{array}$} & Her zaman & 53 & 55,8 \\
\hline & Bazen & 42 & 44,2 \\
\hline \multirow{2}{*}{$\begin{array}{l}\text { Diyabetle ilgili } \\
\text { komplikasyon varlığı }\end{array}$} & Yok & 77 & 81,1 \\
\hline & Var & 18 & 18,9 \\
\hline
\end{tabular}

Tablo 3. Tip 2 diyabetli hastaların BKI ve kan şekerine göre dağılımı ( $n=95)$

BKI

18,5-25 Normal n

9

19

67

${ }^{*} \mathrm{X} \pm \mathrm{SS}$

AKŞ

Kadın

Erkek

TKŞ

Kadın

Erkek
$\%$

9,5

20,0

70,5
${ }^{*} \mathrm{X} \pm \mathrm{SS}=$ ortalama \pm standart sapma

Tablo 1. Tip 2 diyabetli hastaların sosyo-demografik özelliklerine göre dağılımı ( $(n=95)$

\begin{tabular}{|c|c|c|c|c|c|c|c|}
\hline \multicolumn{2}{|c|}{ Sosyodemografik özellikler } & $\mathbf{n}$ & $\%$ & \multicolumn{2}{|c|}{ Sosyodemografik özellikler } & $\mathbf{n}$ & $\%$ \\
\hline \multirow[b]{2}{*}{ Cinsiyet } & Erkek & 33 & 34,7 & \multirow{2}{*}{$\begin{array}{l}\text { Meslek } \\
\text { durumu }\end{array}$} & Ev hanımı/emekli & 81 & 85,3 \\
\hline & Kadın & 62 & 65,3 & & Çalışan & 14 & 14,7 \\
\hline \multirow{5}{*}{ Yaş } & \multirow{2}{*}{$<50$} & \multirow{2}{*}{21} & \multirow{2}{*}{22,1} & \multirow{2}{*}{$\begin{array}{l}\text { Çalışma } \\
\text { durumu }\end{array}$} & Çalışıyorum & 9 & 9,5 \\
\hline & & & & & Çalışmıyorum & 86 & 90,5 \\
\hline & $50-60$ & 39 & 41,1 & Yaşama & Evde yalnız & 7 & 7,4 \\
\hline & \multirow{2}{*}{60 üstü } & \multirow{2}{*}{35} & \multirow{2}{*}{36,8} & durumu & Eş ve/veya çocuklar & 88 & 92,6 \\
\hline & & & & & Okuryazar değil & 55 & 57,9 \\
\hline \multirow{2}{*}{$\begin{array}{l}\text { Medeni } \\
\text { durumu }\end{array}$} & Evli & 90 & 94,7 & \multirow[t]{2}{*}{$\begin{array}{l}\text { Öğrenim } \\
\text { durumu }\end{array}$} & Okuryazar & 31 & 32,6 \\
\hline & Bekâr & 5 & 5,3 & & Ortaokul/lise & 9 & 9,5 \\
\hline
\end{tabular}


Tablo 4. Tip 2 diyabetli hastaların pedigri genetik risk değerlendirmesine göre dağlımı $(n=95)$

$\begin{array}{llll} & & \mathbf{n} & \% \\ \text { Anne-Baba } & \text { Yok } & 67 & 70,5 \\ \text { akraba evliliği } & \text { Var } & 28 & 29,5 \\ \text { Ailede diyabet } & \text { Yok } & 56 & 58,9 \\ \text { varlığı } & \text { Var } & 39 & 41,1 \\ & \text { Yok } & 43 & 45,3 \\ \text { Ailede diyabetin } & \text { 1.dereceden } & 36 & 37,9 \\ \text { kimlerde görüldüğü } & \text { 2.dereceden } & 2 & 2,1 \\ & \text { 1.ve 2. dereceden } & 14 & 14,7 \\ \text { Ailede kronik } & \text { Yok } & 74 & 77,9 \\ \text { hastalık nedeniyle } & \text { Var } & 21 & 22,1 \\ \text { ölüm nedeni } & \text { Evet } & 55 & 57,9 \\ \text { Anne-baba aynı } & \text { Hayır } & 40 & 42,1 \\ \text { köylü olma } & & & \end{array}$

Çalışmada, tip 2 diyabet hastalarında yaşam kalitesi toplam puan ortalamalarının $16,47 \pm 1,61$ olduğu saptandı. Sağlık-fonksiyonel ve Sosyal-ekonomik durum ortalamaları daha düşük puan alırken, Aile durumu puan ortalamasının ise en yüksek olduğu belirlendi (Tablo 5).

Hastaların yaşları ile Yaşam Kalitesi İndeksi Sağlık ve Fonksiyonel Durum alt boyutu arasında negatif yönde anlamlı bir ilişki vardır $(r=-0,248 ; p=0,015)$.
Tablo 5. Tip 2 diyabetli hastaların Ferrans ve Powers'in Diyabet Yaşam Kalitesi Endeksi özellikleri ( $n=95)$.

\begin{tabular}{|c|c|c|c|}
\hline Yaşam kalitesi alt bileşenleri & Min & $\operatorname{Max}$ & ${ }^{*} \mathbf{X} \pm$ SS \\
\hline Sağlık ve fonksiyonel durum & 10,68 & 20,96 & $15,57 \pm 1,61$ \\
\hline Sosyal ve ekonomik durum & 11,96 & 21,25 & $15,82 \pm 2,40$ \\
\hline Fizyolojik ve manevi durum & 8,75 & 21,25 & $16,75 \pm 2,16$ \\
\hline Aile durumu & 13,25 & 21,25 & $18,55 \pm 2,00$ \\
\hline Toplam Puan & 12,37 & 21,18 & $16,47 \pm 1,61$ \\
\hline
\end{tabular}

Hastalarda BKI ile yaşam kalitesi arasında Sağlık ve Fonksiyonel Durum alt boyutu arasında pozitif yönde ilişki bulunmaktadır. Ancak istatiksel olarak anlamlı değildir $(r=0,071 ; p=0,493)$. Hastalarda hastalık tekrar sayısı ile Yaşam Kalitesi İndeksi tüm alt boyutları arasında pozitif yönde anlamlı bir ilişki bulunmaktadır. Fakat istatistiksel olarak anlamlı değildir.( $r=0,155 ; p=0,269$ ) (Tablo 6).

Ailede diyabet görülmesi ile yaşam kalitesi indeksi sağlık ve fonksiyonel durum alt boyutu puan ortalamaları arasında istatistiksel olarak anlamlı bir fark bulundu $(p<0.05)$. Farkın sağlık ve fonksiyonel durum alt boyutunda 1. ve 2 . dereceden aile içinde görülmesinin anlamlı olduğu belirlendi (Tablo 7).

Tablo 6. Tip 2 diyabetli hastaların yaş, BKI ve hastalık tekrar sayısı ile Yaşam Kalitesi Indeksi alt bileşenleri arasındaki ilişki $(n=95)$

\begin{tabular}{|c|c|c|c|c|c|c|}
\hline & & $\begin{array}{c}\text { Sağlık ve fonksiyonel } \\
\text { durum }\end{array}$ & $\begin{array}{c}\text { Sosyal ve ekonomik } \\
\text { durum }\end{array}$ & $\begin{array}{l}\text { Psikososyal } \\
\text { durum }\end{array}$ & $\begin{array}{c}\text { Aile } \\
\text { durumu }\end{array}$ & TOPLAM \\
\hline \multirow{2}{*}{ Yaş } & $\mathbf{r}$ & $-0,248$ & $-0,077$ & $-0,098$ & $-0,078$ & $-0,157$ \\
\hline & $\mathbf{p}$ & 0,015 & 0,456 & 0,345 & 0,450 & 0,129 \\
\hline \multirow{2}{*}{ BKI } & $\mathbf{r}$ & 0,071 & $-0,044$ & $-0,159$ & $-0,072$ & $-0,050$ \\
\hline & $\mathbf{p}$ & 0,493 & 0,675 & 0,124 & 0,490 & 0,632 \\
\hline \multirow{2}{*}{$\begin{array}{l}\text { Tip } 2 \text { diyabet } \\
\text { süresi }\end{array}$} & $\mathbf{r}$ & $-0,041$ & 0,070 & $-0,014$ & $-0,041$ & $-0,005$ \\
\hline & $\mathbf{p}$ & 0,693 & 0,500 & 0,896 & 0,693 & 0,962 \\
\hline \multirow{2}{*}{$\begin{array}{l}\text { Hastalık } \\
\text { tekrar sayısı }\end{array}$} & $\mathbf{r}$ & 0,150 & 0,136 & 0,078 & $-0,093$ & 0,155 \\
\hline & $\mathbf{p}$ & 0,147 & 0,189 & 0,452 & 0,370 & 0,269 \\
\hline arson CoI & & & & & & \\
\hline
\end{tabular}

Tablo 7. Tip 2 diyabetli hastaların Pedigri analizine Göre Yaşam Kalitesi alt boyutları puan ortalamalarının karşılaştırılması $(n=95)$

\begin{tabular}{|c|c|c|c|c|c|}
\hline & $\begin{array}{c}\text { Sağlık ve fonksiyonel } \\
\text { durum }\end{array}$ & $\begin{array}{c}\text { Sosyal ve ekonomik } \\
\text { durum }\end{array}$ & $\begin{array}{l}\text { Psikososyal } \\
\text { durum }\end{array}$ & $\begin{array}{c}\text { Aile } \\
\text { durumu }\end{array}$ & Toplam \\
\hline & *X土SS & ${ }^{*} \mathbf{X} \pm$ SS & ${ }^{*} \mathbf{X} \pm \mathbf{S S}$ & ${ }^{*} \mathbf{X} \pm \mathrm{SS}$ & ${ }^{*} \mathbf{X} \pm \mathbf{S S}$ \\
\hline Aile içinde görülmeyen & $15,42 \pm 1,74$ & $15,52 \pm 2,28$ & $16,62 \pm 2,06$ & $18,35 \pm 1,96$ & $16,48 \pm 1,50$ \\
\hline 1. dereceden & $15,68 \pm 1,89$ & $15,87 \pm 2,48$ & $16,59 \pm 2,27$ & $18,43 \pm 2,01$ & $16,64 \pm 1,65$ \\
\hline 1. ve 2. dereceden & $16,88 \pm 1,17$ & $17,54 \pm 1,98$ & $18,07 \pm 1,86$ & $17,76 \pm 2,11$ & $17,56 \pm 1,62$ \\
\hline \multirow{2}{*}{ *KW / p } & 10,382 & 8,756 & 6,594 & 1,473 & 4,829 \\
\hline & 0,006 & 0,013 & 0,037 & 0,479 & 0,89 \\
\hline *Kruskal Wallis Test & \multicolumn{5}{|c|}{${ }^{*} \mathrm{X} \pm \mathrm{SS}=$ ortalama \pm standart sapma } \\
\hline
\end{tabular}




\section{Tartışma}

Tip 2 diyabet genetiğinde ilerlemelerin en önemli klinik yararlarından biri, genetik verilerin kullanılarak hastalığın gelişme riskinin tahmin edilebilmesi olarak öngörülmektedir. Bu sayede erken müdahale stratejilerinin geliştirilebilmesi ve diyabetin önlenmesi ya da başlangıcının geciktirilmesi mümkün olabilir. Bu amaçla pek çok çalışmada, tip 2 diyabette yatkınlık oluşturduğu düşünülen ve bağımsız kalıtım varyantlar toplanarak, bu genetik bilginin kullanılması ile ortaya çıkan tahmin yeteneğinin değerlendirilmesi için genetik risk puanlama modelleri oluşturulmuştur (Arıkoğlu ve Kaya, 2015; Qi ve Hu, 2012)

Hastalığın ortaya çıkışı ve ilerleyişinde etkin olan çevresel faktörler ve bunların etki mekanizmalarının ya da gen-çevre etkileşiminde iş gören faktörlerin ne olduğu henüz tam olarak aydınlatılamamıştır (Arıkoğlu ve Kaya, 2015). Tip 2 diyabetli hastalarda pedigri analizi ile risk faktörleri ile yaşam kalitesi ilişkisinin incelendiği bu çalışmada; hastaların çoğunluğunda eşlik eden kronik hastalık ve anne-babada akraba evliliği bulunmamakta önemli bir kısmının ailesinde 1. dereceden kişilerde diyabet görülmektedir.

Scot ve arkadaşlarının (2018) çalışmasında katılımcıların yaklaşık üçte birinin \%29,6'sının ailesinde tip 2 diyabet öyküsü olduğu belirlenmiştir. Bu çalışmada ise \%39'unda ailede tip 2 diyabet varlığı bulunmaktadır. Bizim bulgularımızın Scot ve arkadaşlarının 2018 yılında yaptığı çalışma sonuçlarından daha yüksek olduğu belirlendi. Bunun nedeninin beslenme alışkanlıkları, kültürel farklılıklar ve çalışmanın farklı popülasyonlara yapılması ile ilişkili olduğu düşünülmektedir (Scot vd. 2018).

Bayram (2010)'un yaptığı çalışmada diyabetli bireylerin en yüksek puanı sağlık ve fonksiyonel durum bileşeninden aldığı saptanırken, en düşük puan ortalamalarını ise aile durumundan aldığı bulunmuştur. Bu çalışmada ise sağlık-fonksiyonel ve sosyal-ekonomik durum ortalamalarından en düşük puanı alırken, aile durumu ortalamalarında ise en yüksek puan ortalamalarına sahip olduğu belirlendi. Sonuçlar bu çalışmadaki bulgumuzla uyuşmamaktadır. Nitekim bu sonuçlar, diyabette yaşam kalitesinin başka değişkenlerden etkilenebileceğini düşündürmektedir.

\section{Sonuç ve Öneriler}

Tip 2 diyabet hastalarında, genetik risk faktörleri ve yaşam kalitesi arasındaki ilişki aile soy geçmiş̧inin değerlendirilmesi ile hastalığın gelecekteki seyri açısından önemli olabileceği düşünülmektedir. Hastalık gelişmeden önceki dönemde risk altındaki bireylerin yönetiminin sağlaması ve soy geçmiş öyküsünün tanılamasının maliyet açısından etkin sonuçlar ortaya çıkaracağı tahmin edilmektedir.

Genetik riskin belirlenebilmesi açısından klinikteki kullanımını sağlamak için, örneklemi büyük gruplarda çalışılması önerilebilir. Bununla birlikte, genetik riskin yaşam kalitesine etkisini belirlemek için hastaların ve yakınlarının kurumlarda sağlık kayıtlarını ve aile öykülerini de kapsayacak düzenli bir şekilde kayıt altına alınması gerektiği önerilebilir.

Çıkar Çatışması: Yazarlar arasında herhangi bir çıkar çatışması bulunmamaktadır.

Yazarlık Katkıları: Konsept: I.C.D., N.O.; Dizayn: I.C.D., N.O.; Veri Toplama veya İşleme: I.C.D., İ.A.; Analiz veya Yorumlama: İ. C.D., N.O.; Literatür Arama: I.C.D., N.O.; Yazan: I.C.D.

\section{Kaynaklar}

1. Arıkoğlu, H. ve Kaya, D. E. (2015). Tip 2 diyabetin moleküler genetik temeli; Son gelişmeler. Genel Tıp Dergisi, 25(4). 147-159

2. Barroso. I. (2005). Genetics of Type 2 diabetes. Diabetes UK. Diabetic Medicine, 22, 517-535.

3. Bayram, D. (2010). Tip 2 diyabetli hastalarda uyku kalitesi ve yorgunluk düzeyinin yaşam kalitesi üzerine etkisi. Yüksek Lisans Tezi, Bolu İzzet Baysal Üniversitesi Sağlık Bilimleri Enstitüsü, Bolu.

4. Calzone, K. A., Jenkins, J., Bakos, A. D., Cashion, A. K., Donaldson, N., Webb, J. A. (2013). A blueprint for genomic nursing science. Journal of Nursing Scholarship, 45(1), 96-104.Chernausek, S. D., Arslanian, S., Caprio, S., Copeland, K.C., Kelsey, M.M., Koontz, M. B. ve Wilfley, D. (2016). Relationship between parental diabetes and presentation of metabolic and glycemic function in youth with type 2 diabetes. Diabetes care, 39(1), 110-117.

5. Doi, T., Ninomiya, J., Hata, Y., Hirakawa, N., Mukai, M., Iwase Y. and Kiyohara. (2011). Two risk score models for predicting incident Type 2 Diabetes in Japan. Diabetic Medicine. 29(1), 107-114.

6. Durmaz, B., Durmaz, A. A., Özkınay, F. ve Coğulu, Ö. (2011). Genetic Counseling and Its Importance. Cumhuriyet Tıp Dergisi, 33(2), 259-265.

7. Efe, E. ve Canlı, Z. (2006). Validity and reliability of the Turkish version of the ferrans and powers quality of life index diabetes version. Saudi medical journal, 27(1), 123-125.

8. Ferrans, C. E. (2008). Ferrans and powers quality of life index (QLI). Retrieve August 25,2021, from http://qli.org.uic.edu/index.htm

9. Hopper, J. Bishop, T. ve Easton, D. (2005). Genetic epidemiology: population - based family studies in genetic epidemiology, The Lancet, 366, 13981406.

10. Karadağ, Ö. ve Aktaș, S. (2017). Genetik çalışmalarında ailesel yakınlıkların ölçümü için sınıf-içi ve sınıflar-arası korelasyon katsayıları. İstatistikçiler Dergisi: İstatistik ve Aktüerya, 10(2), 96-103.

11. Kong, $X$, Xing, $X$, Hong, J, Zhang, $X$ ve Yang, W. (2017). Association of a type 2 diabetes genetic riskscore with insulin secretion modulatedby insulin sensitivity among Chinese Hans. Clin Genet. 91: 832-842.

12. Luciano, M., Mo 凶ttus, R., Harris, SE. Davies, G., Payton, A. ve Deary, İ. J. (2014). Predicting cognitive ability in ageing cohorts using Type 2diabetes genetic risk. Diabet. Med, 31; 714-720.

13. McPherson, E. (2006). Genetic diagnosis and testing in clinical practice. Clin Med \& Res, 4: 123-9.

14. Olgun, N., Özkan, S., Satman, I., Yetkin, İ., Çalışkan, D., Özcan, Ş. ve Özer, E. (2014). Erişkin Diyabetli Bireyler İçin Eğitim Rehberi. Sağlık Bakanlığı. Ankara: Koza basım yayın, Ltd. Sti.

15. Osman, A. O. (2020). Üniversite öğrencilerinde Tip 2 diyabet riski, davranışsal ve ailesel risk faktörleri ile Tip 2 diyabet farkındalığı. Yüksek Lisans Tezi, Aydın Adnan Menderes Üniversitesi Sağlık Bilimleri Enstitüsü, Aydın.

16. Özkan, S. ve Arslan, FT. (2019). Hemşirelik ve Ebelik Öğrencilerinin Genetik Danışmanlık Rolleri ile İlgili Görüşleri. Acıbadem Sağlık Bilimleri Dergisi, 10(2), 225-230.

17. Qi, Q. ve Hu, F.B. (2012). Genetics of type 2 diabetes in European populations. J Diabetes 4(3),203-12.

18. Raghavan, S., Pachucki, M. C., Chang, Y., Porneala, B., Fox, C. S., Dupuis, J. ve Meigs J. B. (2016). Incident type 2 diabetes risk is influenced by obesity and diabetes in social contacts: a social network analysis. Journal of General Internal Medicine, 1-7.

19. Saleh, M., Kerr, R. ve Dunlop, K. (2019). Scoping the Scene: What do Nurses, Midwives and Allied Health Professionals need and want to know about Genomics?. Frontiers in genetics, 10, 1066.

20. Sevinç, S., Akın, H. ve Uzun, Ö. (2018). Akut koroner sendromlu hastalarda pedigri analizi ile risk faktörleri yaşam kalitesi ve hastalık ilişkisi. Turk J Cardiovasc Nurs, 9(18), 13-19.

21. Skot, L., Nielsen, J. B. ve Leppin, A. (2018). Who perceives a higher personal risk of developing Type 2 diabetes? A cross-sectional study on associations between personality traits, health-related behaviours and perceptions of susceptibility among university students in Denmark. BMC Public Health, 18(1), 1-10.

22. Yalın, H., Demir, H. G. ve Olgun, N. (2011). Diyabetle mücadelede diyabet risklerinin belirlenmesi ve tanılama. The Journal of Turkish Family Physician, 2(2), 41-49.

23. Yoo, H. W. (2010). Genetic testing in clinical pediatric practice. Korean Journal of Pediatrics, 53(3), 273-285.

24. Yu, W., Hu, C. ve Jia, W. (2012). Genetic advances of Type 2 Diabetes in Chinese populations. Journal of Diabetes, 4(3), 213-220. 